\title{
The Impact of a Good Family Sports Climate on Children's Character Building
}

\author{
Xiadi Lyu ${ }^{1}$ and Xinyu Lian ${ }^{2, *}$ \\ ${ }^{1}$ Department of Physical Education, Taiyuan Normal University, Taiyuan, China \\ ${ }^{2}$ Department of Physical Education, Taiyuan Normal University, Taiyuan, China \\ *Corresponding author. Email: Y13834613532@163.com
}

\begin{abstract}
Family education is the foundation of all education. With the development and progress of today's society, parents are paying more and more attention to the family education of their children. As an important part of family education, physical education has become an important part of family education. In this paper, we analyze the influence of family sports on the development of children's character, which is the most important stage in the development of children's character, and hope that it will help to improve the problems of children in China.
\end{abstract}

Keywords: Family sports climate, Children, Personality

\section{THE INFLUENCE OF THE FAMILY ON THE CHILD'S PERSONALITY}

The family is the basic cell of the social structure and has an irreplaceable special position and active role in promoting the development and construction of the material and spiritual civilization of the society. Parents are the initiation teachers of their children [1]. Family education is not only the first step in the development of life, but also an important process that accompanies the growth of a person from birth to infancy, early childhood, adolescence and youth.

In family education, parents are the givers of education, their life concepts and values will become the mainstream in the whole family culture, and their concepts, attitudes and behaviors influence their children's values, ideologies, etc. in the ordinary life communication [2]. In children's minds, what parents say and do is considered an authority, and they will imitate and learn and accept these behaviors and lifestyles, and these values will be deeply imprinted in their early years of growth.

\section{SPORTS AND CHILDREN'S PERSONALITY}

The 19th Party Congress pointed out that we should fully implement the Party's education policy, implement the fundamental task of establishing moral education, develop quality education, promote educational equity, and cultivate socialist builders and successors who are well-rounded in moral, intellectual, physical and aesthetic development [3]. Sports can not only improve children's physical fitness, but also have a positive impact on their character. Sports not only improve children's physical fitness, but also have a positive impact on their character.

\subsection{What is personality?}

Personality is an important part of personality and is relatively stable in the way an individual behaves. The definition of personality in psychology can be understood as follows: personality is the psychological characteristics of a person's personality expressed in stable attitudes and behavior toward reality [4].

Personality reflects the individual's worldview and values. Character is not only the attitude and view of nature, society and life, but also the comprehensive performance of thinking style and dealing with people [5]. As an individual grows up, his or her personality may change or be reshaped as the scope of contact with social life expands and is influenced by other factors such as the environment. As we grow up, we are bound to come into contact with our environment. The environment is not only the situation and conditions of an individual's life, but also a state of communication between people and their hearts. Individuals will think, will evaluate the things around them, slowly over time, the character will be unconsciously changed. 


\subsection{Formation of children's character}

People are not born with character, but gradually formed and developed as they grow up. Child psychologists, after long-term research and investigation, found that the golden stage of character formation is childhood, and the foundation of various behavioral habits is laid during this period. If the child's character is neglected at this stage, it will be more difficult to have a sound personality and a healthy mind as an adult. Character is formed from infancy to about 11 years old, which is what we call childhood. During this stage, children's character, self-control, moral values and behavioral habits are gradually developed. However, character is easily influenced by the environment in the process of formation, so the environment plays an important role in shaping character.

The character of the child is born on the basis of the physical and spiritual environment [6]. In the past, too much attention has tended to be paid to the physical environment in which children live, while neglecting the role of the spiritual environment, or culture. Family culture, in turn, directly influences the child's cognitive and emotional reflections. Since sports can help children's psychological and social adaptation development, the family sports climate is also one of the environmental factors that shape children's character.

\subsection{Family sports atmosphere on the shaping of personality}

Sports behavior is a special way of human activity, his formation and development, by the joint influence of physiological, psychological and external factors. Sports behavior is the purposeful and conscious use of various means and methods of human activity to meet certain sports needs. It is a relatively broad concept, that is, all behavioral activities associated with sports, can be called sports behavior.

On another level, sport also includes both explicit and implicit aspects. Explicit sports behaviors are more associated with the physical activity level, while implicit sports behaviors are more related to the psychological level, mainly in terms of attitudes values, needs and motivations, etc. In the following we focus on the main aspects of implicit behaviors sports influence on children's personality development.

\subsubsection{Inspiration of sports}

People with high emotional intelligence are able to understand themselves properly, control their emotions and interact well with others. Children perceive and understand the world through participation in sports, and their parents are the best partners in their development as participants. In addition to bringing immense joy to children, sports also play a role in inspiring diversity in children's personalities [7]. Let children experience the process of movement from an early age, so that children can understand knowledge faster and develop a scientific way of thinking; in the process of repeated exploration, children develop their logical thinking skills, imitation, observation, language skills, and even survival skills, which are based on the improvement of thinking skills, that is, to promote the development of intelligence. At the same time, sports can also bring infinite joy to children, through the visualization, visual education and children's physical participation, not only can make children open their eyes, enhance intelligence, accelerate physical development, but also cultivate children's social interaction skills, and promote the perfection of good character.

\subsubsection{Exercise of sports}

Sports are a necessary gateway for children's character development and have an important impact on their character formation and development. A positive family sporting environment provides children with more opportunities to participate in sporting activities, which helps children to be more playful, stable and active, and to have higher levels of mental health assessment [8]. Diversified sports activities help children identify their own strengths and weaknesses, strengthen their perseverance and tenacity, and develop a strong will in their character; they also help them develop their communication and coordination skills, which leads to better development of physical and mental health. During childhood, more play activities are the main focus, so that children's character characteristics can be fully reflected and developed, but also conducive to the correct assessment of young people themselves, enhance self-confidence and self-esteem. This shows that sports have a prominent role in the development of children's character.

\subsubsection{Normality of sports}

Humans are not born with a sense of rules and norms. Children's behavioral norms are developed through education. Sports are highly competitive in nature, and children are bound by the rules of sports while experiencing the joy it brings. They learn how to follow the rules of behavior while participating in competition, which builds a healthy competitive mindset and also allows children to fully experience the spirit of faster, higher and stronger sports. Norms of behavior enable people to follow social norms and act appropriately regardless of the situation they are in [9]. And for children, norms of behavior are an important part of building good character. A positive family sporting environment allows children to appreciate the importance of norms through a variety of sporting activities. 


\subsubsection{Social aspect of sports}

By participating in sports activities, children increase their own opportunities for social contact. During the practice, parents play, learn and communicate with their children, allowing them to experience the social education function of sports. A good family sports atmosphere increases children's desire to participate in the real world, satisfying their need for movement development, venting energy and psychological satisfaction. The diversity of sports also helps young people build complete and healthy personalities. A good family sports atmosphere increases children's desire to participate in the real world, satisfying their need for movement development, venting energy and psychological satisfaction. The diversity of sports also helps young people build complete and healthy personalities [10]. For example, basketball activities require not only the accuracy of one's own shooting, but also the flexibility and resourcefulness, the courage to fight and the sense of cooperation and unity among team members. Sports such as soccer, basketball and tug of war, which require the cooperation of many people, play an important role in the development of a sense of the big picture among young people. Regular participation in sports during childhood enhances social skills, communication skills, and can help them better understand their relationship with society. Therefore, special physical exercise for children with different characteristics has an important impact on the development of their character. For those children who do not want to communicate with others, they can choose to participate in soccer, basketball, tug of war and other sports that require the cooperation of many people to enhance the ability to communicate with others socially under natural conditions, so as to change the introverted and withdrawn personality.

\section{CONCLUTION}

As an important participant in the development of children's personalities, the family has an active role to play in enhancing the positive impact on children's personalities through moderate participation in sports [11]. It is important to focus on sports for children so that they can participate in a variety of sports to learn about themselves, assess themselves, increase their selfconfidence and self-esteem, and develop their physical and psychological well-being.

First, ideological importance. Parents should change their mindset and raise the importance of sports and recognize the impact of sports on the development of children's character, thus fundamentally increasing the possibility of their children's participation in sports activities.

Secondly, change the education method. A good family sports atmosphere can create a positive and healthy environment for children to grow up, so that children in the important stage of character development is not only physical enhancement, but also to sharpen their will, promote their own character to further improve and develop, and form a healthy personality.

\section{ACKNOWLEDGMENTS}

The whole process from determining the topic, collecting data, writing and revising to the final draft was full of doubts, pressure and fun. First of all, I would like to thank my lover, Peng Liu, for his encouragement and support, which gave me the confidence to persist in this almost new field of research and complete the paper successfully.

In the process of writing this paper, Ms. Lianxin $\mathrm{Yu}$ provided me with good academic support because of her rigorous academic discipline, extensive knowledge and broad vision. Thanks to her many times of reviewing the full text, revising the details, and providing many pertinent and valuable comments for the writing of this paper, this paper has been shaped.

In addition, this paper refers to a large number of magazines and journals and professional series, due to the reference to too many journals, I can not specify them all, please forgive and to all authors and publications to express my sincere gratitude! Due to my limited level, I am inevitably wrong, so I would like to ask all scholars for their advice.

\section{REFERENCES}

[1] J.L. Han, Home-schooling guidance (below). Shandong Electronic Audio and Video Publishing House, 2002.

[2] L.Y. Ma, An introduction to the influence of family education on the formation of children's character. Science Times, vol.216, 2010, pp.286-287.

[3] X. Li, On the Influence of Family Education on the Formation of Children's Personality. The Science Education Article Collects, 2019.

[4] L.J. Gao, H.J. Cao, Cultivation of Japanese children's awareness of behavioral norms-from the perspective of garbage classification. Science Education Journal (mid-day issue).

[5] Deng Ting. (2020). Value Judgment and Personality Traits of Individual Innovation Behaviors-Book Review of Personality Traits, Life Styles and Innovative Behaviors. Journal of Yangtze University (Social Science Edition), v.43; No. 225 (02), 131-131.

[6] Zhang Xiaohong. (2020). On the importance of the family environment for the growth of 
children. Economic and Social Development Research (3), 0288-0289.

[7] Y.M. Yang, On the impact of sports games on the healthy personality of preschool children. Zhejiang Sports Science vol. 04, 2005, pp.54-56.

[8] H.Y. Zhang, Teaching research on the cultivation of sound personality in ideological and moral courses. (Doctoral dissertation, Guangxi Normal University).
[9] J.M. Xu, D.M. Gong, An analysis of the influence of sports on the development of adolescent character. Science Public (Science Education), vol.1076, 2018, pp.176-177.

[10] J.N. Huang, S.K. Chen, S.H. Liu, The relationship between parental behavior, personality and child behavior. Chinese Journal of Social Medicine, vol. 157, 2001, pp.18-20.

[11] C.X. Lin, The significance of developing the selfcare ability of left-behind children in rural kindergartens. 